\title{
EXPERIMENTAL STUDY ON THE RATE OF ABSORPTION OF WATER OF BASALT, POLYPROPYLENE AND STEEL FIBERS REINFORCED CONCRETE
}

\author{
Mustapha Abdulhadi' and S.I. Haruna*
}

\begin{abstract}
1. School of mechanic, Civil Engineering and Archtichture Northwestern Polytechnic University Xi'an 710071 P.R. China

2. Department of Civil Engineering, Bayero University, Kano P.M.B. 3011, Nigeria, siharuna.civ@buk.edu.ng
\end{abstract}

\begin{abstract}
Good durability of concrete is an essential part of the design process, and durability designs are carried out by specifying material requirements and the exposure conditions in which the structure is in contact. The main feature of durable concrete is low water absorption. Almost all forms of deterioration in reinforced concrete involve harmful fluid ingress through the concretes pore structure. In wet concrete, the water ingress rate or other liquids is mainly controlled by absorption due to capillary rise. This study examines the effect of basalt, polypropylene, and steel fiber in different volume fractions $\left(\mathrm{V}_{\mathrm{f}}\right)$ of $0.3 \%, 0.6 \%$, and $0.9 \%$ for absorption tests. A total of 8 specimens for different fiber volume fractions were examined based on the rate of water absorption test recommended by ASTM C1585-04. A result obtained has been analyzed and compared with the control specimen. A relationship between absorption rate and the square root of time for both concrete mixtures was represented graphically and linearly. Result data showed a precise decrease in absorption due to incorporating both types of fiber. Also, basalt and polypropylene showed greater uptake than steel fiber and enhanced water transport into concrete specimens from the result data. However, steel fiber showed high resistance to absorption rater than the control specimen and other fiber.
\end{abstract}

\section{KEYWORDS}

Basalt fiber, Water absorption, Polypropylene fiber, Steel fiber

\section{INTRODUCTION}

The durability of concrete mostly depends on how fluids penetrate the concrete matrix. For instance, damage caused due to the present chloride ions in de-icing salts or seawater. The durability of concrete is affected by pore structure. The porosity and connectivity of the pore play a vital role in the permeability of concrete. The experimental test results are widely used as a factor for concrete durability has been adopted in the past study $[1,2]$.

$0.05 \%$ by volume fraction of Polypropylene fiber is considered the optimum amount of polypropylene fibers to be added to concretes mixture due to its excellent performance at elevated temperature [3]. Improving the hardened property, the mainly compressive strength of concrete does not enhance its behavior, especially tensile strength and strains. [4]. The behavior of self fiber compacting concrete was affected by incorporating silica fume [5]. Steel fiber showed the best resistance to the damaging effect of $\mathrm{NaCl}$ than other types of fiber and control specimens as its compressive strength increased by $0.6 \%$ and $0.9 \%$ by $4.6 \%$ and $16.4 \%$, respectively. That might result from relatively high bonding, which blocked water and $\mathrm{NaCl}$ solution from traveling between fiber and hardened concrete [6]. The basalt aggregate was used in slurry infiltrated fiber concrete 


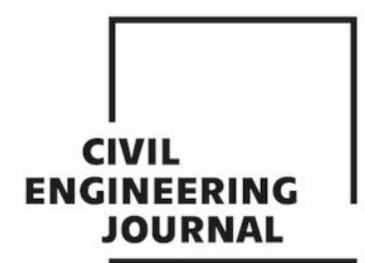

Article no. 31

THE CIVIL ENGINEERING JOURNAL 2-2021

[7]. The anti-cracking behavior of steel fiber in steel fiber ceramic concrete was enhanced with fiber content [8]. Niveditha and Srikanth [17] study the effect of mineral admixture on the hardened properties, water absorption rate, and permeability in geopolymer concrete. They reported that the addition of ultra-fine slag enhances the durability properties.[9]

The investigating parameters such as permeability, diffusivity, and rate of water absorption behavior are vital for the durability of concrete [10]. Sorptivity, the rate of water absorption, is a rapid and simple test that can indicate the transport properties of cover concrete and its tendency to absorb and transmit water by capillarity [11]. The water absorption varies mainly depending on the cement paste aggregate in the concrete mixture [12]. Four requirements must be met for the water absorption vs. $\sqrt{t}$ Law to hold, [13]: (I) homogeneous material is required on the penetration distance scale, (II) The capillary absorption flow, (III) the availability of water to flow at the inflow

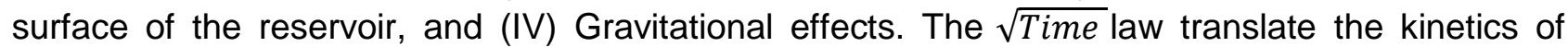
capillary absorption (sorptivity). Other factors that can affect the sorptivity values of concrete are the sorptivity properties of the individual components of the mix, such as the cement paste matrix and its physical arrangement, for example, the aggregate distribution [13]. In this study, the absorption rate of water of concrete mixtures incoprated with basalt, polypropylene, and steel fiber were evaluated. And the method involved in determine the increase in the mass of a specimens that results from the absorption of water as a function of time when only one surface of specimens is under water.

\section{EXPERIMENTAL PROGRAM}

\section{Material}

Ordinary cement $(42.5 \mathrm{~N})$ was used to prepare concrete mixtures; Table 1 shows the properties of aggregates used in the study, following the international standard [14]. Natural river sand with a specific gravity of 2.60 was used as fine aggregate. A natural stone with a nominal size of 15-20 mm was used as a coarse aggregate. The cement, sand, coarse aggregate, and water content were $407,535,1245$, and $203.7 \mathrm{~kg} / \mathrm{m}^{3}$, respectively, prepare to achieved C30 concrete according to [15]. The three specific fibers, namely: basalt, polypropylene, and straight steel fiber, as shown in Figure 1, were used in the study.

Tab. 1 - Properties aggregates used

\begin{tabular}{|l|l|l|l|l|}
\hline Materials & $\begin{array}{l}\text { Apparent density } \\
\left(\mathrm{kg} / \mathrm{cm}^{3}\right)\end{array}$ & $\begin{array}{l}\text { Apparent density } \\
\left(\mathrm{kg} / \mathrm{cm}^{3}\right)\end{array}$ & $\begin{array}{l}\text { Fineness } \\
\text { modulus }\end{array}$ & $\begin{array}{l}\text { Moisture content } \\
(\%)\end{array}$ \\
\hline Coarse aggregate & 2665 & 1450 & - & - \\
\hline Fine aggregate & 2670 & 1554 & 2.46 & 3.1 \\
\hline
\end{tabular}

Tables 2 and 3 present the fibers' performance behavior to fabricate the fiber-reinforced concrete mixture. The average compressive strength of the reference sample and fiber reinforced concrete specimens were also presented in Table 3. 


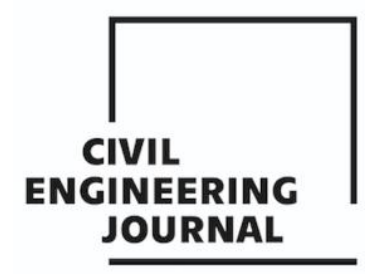

Article no. 31

THE CIVIL ENGINEERING JOURNAL 2-2021

Tab. 2 - performance Properties of fibers used

\begin{tabular}{|l|l|l|l|}
\hline \multicolumn{1}{|c|}{ Property } & Basalt & Polypropylene & Steel fiber \\
\hline Length $(\mathrm{mm})$ & 18 & 12 & 13 \\
\hline Diameter $(\mathrm{mm})$ & 0.013 & 0.021 & 0.2 \\
\hline Aspect ratio (I/d) & 1384 & 544 & 65 \\
\hline Tensile strength (MPa) & $3000 \sim 3500$ & $365 \sim 600$ & 2900 \\
\hline Ultimate elongation (\%) & 3.2 & $25 \sim 60$ & 4 \\
\hline Density (g/cm $\left.{ }^{3}\right)$ & 2.65 & 0.9 & 7.8 \\
\hline Modulus of Elasticity $(\mathrm{GPa})$ & $90 \sim 110$ & $2.4 \sim 3.2$ & 210 \\
\hline
\end{tabular}
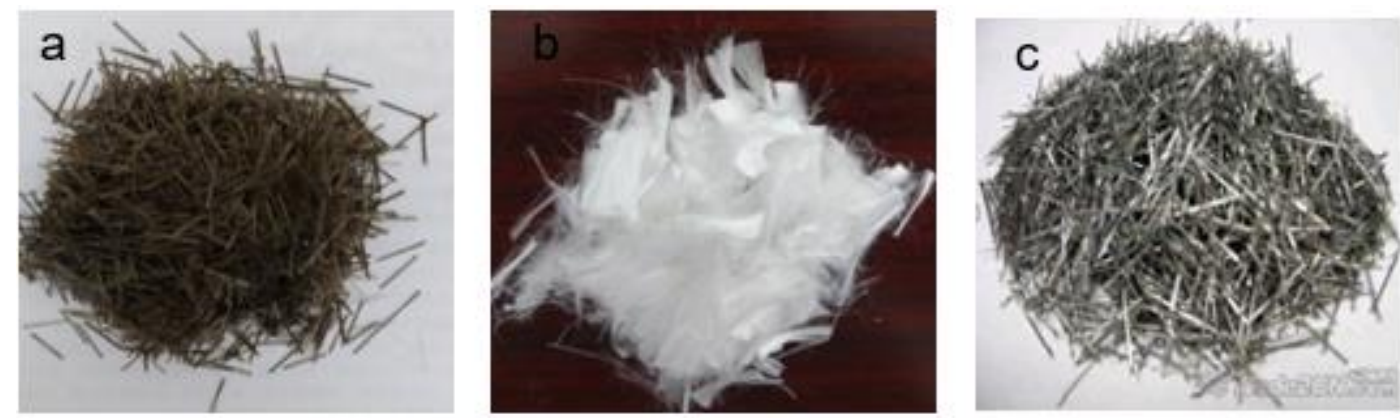

Fig.1- Fiber type: (a) Basalt fiber (b) PP fiber, (c) Steel fiber

\section{Mixing and sample preparation}

The mixing of non-fibrous and fiber reinforced concrete was described as follows: first, the constituent materials, including coarse aggregate, fine aggregate, and cement, were mixed dry in a concrete mixer for about 2 minutes. Subsequently, water was added gently to the mixture, while mixing was continued for the next 1 minute. The fibers were scattered into the concrete mixture to prevent the fiber clotting., the mixing was continued for another 3 minutes to obtain homogeneous concrete mixtures. For absorption test, eight $185 \times 150 \mathrm{~mm}$ cylinder specimens were produced with fiber volume fraction of $0.0 \%, 0.3 \%, 0.6 \%$, and $0.9 \%$, respectively. While for the compressive strength test, three $150 \times 150 \times 150 \mathrm{~mm}$ Cubic specimens were cast for each fiber volume fraction. The average of samples from each mixing condition was taken as the compressive strength as shown in Tab. 4. After 24 hours, all the samples were removed and cured at the standard curing room for 28 days. The cylinder specimens were prepared for the water absorption test. 


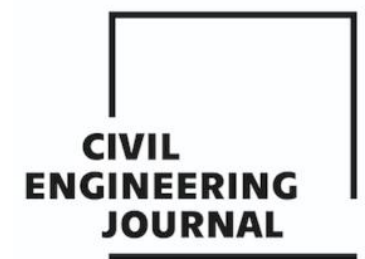

Article no. 31

THE CIVIL ENGINEERING JOURNAL 2-2021

Tab. 3: The compressive strength results of fiber reinforced concrete mixtures.

\begin{tabular}{|l|l|c|c|c|}
\hline Specimen & Type of Fiber & $\begin{array}{c}\text { Fiber volume } \\
\text { fraction } \mathrm{V}_{\mathrm{f}}(\%)\end{array}$ & Number of specimens & $\begin{array}{c}\text { Average } \\
\text { Compressive } \\
\text { strength (MPa) }\end{array}$ \\
\hline Plain/Control & - & 0.0 & 3 & 35.55 \\
\hline BFRC & Basalt & 0.3 & 3 & 32.02 \\
\hline & & 0.6 & 3 & 33.24 \\
\hline & & 0.9 & 3 & 35.86 \\
\hline PFRC & Polypropylene & 0.3 & 3 & 33.44 \\
\hline & & 0.6 & 3 & 33.27 \\
\hline SFRC & & 0.9 & 3 & 29.92 \\
\hline & & 0.3 & 3 & 37.95 \\
\hline & & 0.6 & 3 & 43.82 \\
\hline
\end{tabular}

Compressive strength for concrete cube specimen with $0 \%, 0.3 \%, 0.6 \%$, and $0.9 \%$ of Basalt, Polypropylene, and Steel Fibers are shown in Table 3.

As seen from the table, the addition of $0.3 \%$ and a $0.6 \%$ volume of Basalt fiber resulted in decreased compressive strength relative to plain concrete by $9.9 \%$ and 6.5 . At the same time, $0.9 \%$ volume of Basalt fiber indicates a slight increase in compressive strength (i.e., $0.9 \%$ ). Similarly, the addition of $0.3 \%, 0.6 \%$, and $0.9 \%$ volume of polypropylene fiber resulted in a decrease of compressive strength relative to plain concrete by $5.9 \%, 6.4 \%$, and $15.8 \%$, respectively. For steel fiber, addition of $0.3 \%, 0.6 \%$ and $0.9 \%$ resulted in an increase in compressive strength by $6.8 \%$, $23.3 \%$ and $28.1 \%$ respectively. The addition of polypropylene and basalt fibers in the concrete mixture has different degrees of reducing compressive strength. Several factors affect the strength of concrete, such as cement strength, water-cement ratio, and the size of the concrete aggregates [14]. The incorporation of the fibers within the concrete matrix changes the phase of each component. As seen from the test results analysis, with the same series of fiber concrete, the strength decreases with the increase of fiber mixing ratio increases; also, with the same volume of fiber, different series of fiber results in different compressive strength of concrete.

\section{Testing procedure}

The water absorption rate of fiber reinforced concrete mixtures was conducted according to [16] ASTM C1585-04. The influence of fiber volume fraction and fiber type were evaluated accordingly. The water intake led to an increase in the mass of a specimen due to the capillary action of water expressed as a function of time, subjecting only one surface of the sample to water, and the top surface was sealed (candle wax). The water absorption is calculated using Eq. 1. For this study, the temperature variation was considered constant, and $0.001 \mathrm{~g} / \mathrm{mm}^{3}$ is taken as water density.

$$
I=\frac{m t}{A \times \rho_{w}}
$$

Where $I, m t, \rho_{w}$ And $A$ are the water absorption in $(\mathrm{mm})$, change in specimen mass $(\mathrm{g})$ at a time t, density of water $\left(\mathrm{g} / \mathrm{mm}^{3}\right)$, and exposed area of the specimen $\left(\mathrm{mm}^{2}\right)$, respectively.

The square root of time relationship controls the water transport into the concrete by capillarity. The initial rate of absorption $\left(\mathrm{mm} / \mathrm{s}^{-2}\right)$ was defined as the slope of the line that is the best fit to I plotted against the square root of time $\left(\mathrm{S}^{-2}\right)$. This slope is obtained using the least-squares, linear regression method of the plot of $I$ versus time $\mathrm{S}^{-2}$. A schematic setup of the capillary suction 


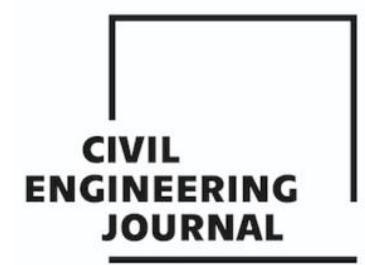

Article no. 31

THE CIVIL ENGINEERING JOURNAL 2-2021

test is shown in Figure 2. A cylindrical specimen was placed on the support device at the bottom of the pan, filled with tap water, then the water level was maintained 1 to $3 \mathrm{~mm}$ above the top of the support device. The absorbed water quantity was recorded at different time intervals as indicated in Tab.le4 through 6 . Any surface water was blotted off with a dampened paper towel for each mass determination.

Linear regression was used to determine the slope. The experimental setup of the capillary action test is depicted in Figure 2. The test specimens were put on the pan filled with water and supported by a device. The water level was kept at a height ranging from 1 to $3 \mathrm{~mm}$ above the top of the support device. The absorbed water quantity was monitored at different time interval indicated in Table 4.

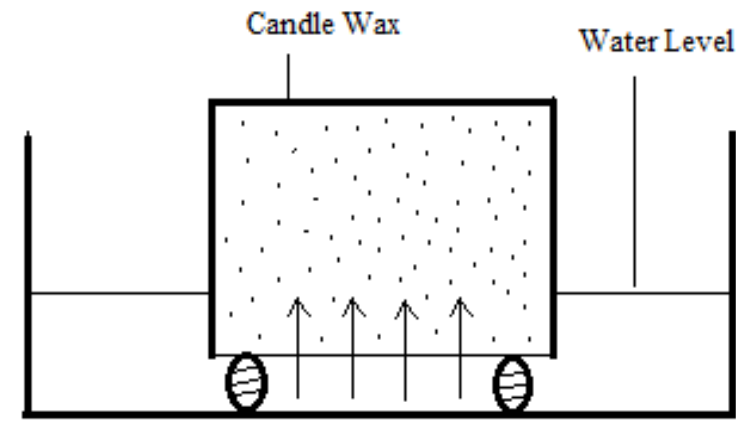

A schematic setup

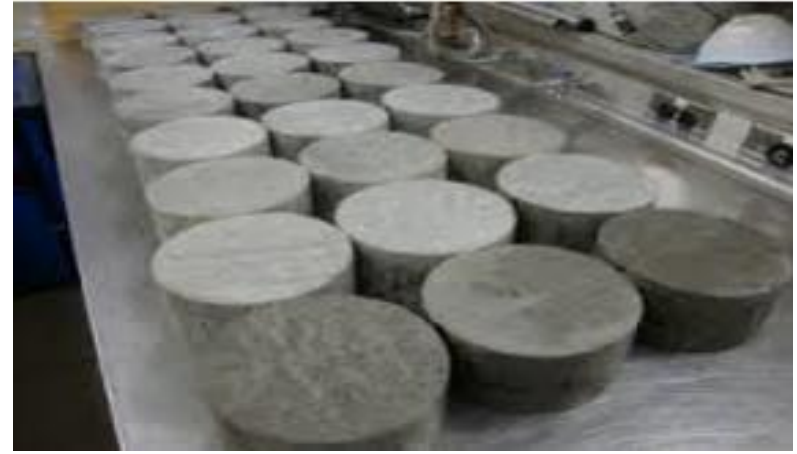

Cylindrical specimens

Fig. 2- Experimental Setup

\section{RESULT AND DISCUSSION}

\section{Water absorption}

The result of the water absorption test of non-fibrous and fiber reinforced concrete cylinder specimens incorporated with $0 \%, 0.3 \%, 0.6 \%$, and $0.9 \%$ of basalt, polypropylene, and steel fibers are summarized and given in Tables $4-6$. The square root of time relationship monitors the water absorption in concrete specimens by capillarity action. The initial rate of water absorption $\left(\mathrm{mm} / \mathrm{s}^{1 / 2}\right)$ described the slope of the line drawn on the graph of absorption versus the square time $\left(s^{1 / 2}\right)$. Slop was obtained by using least-square linear regression analysis from the plot of $I$ versus the square root of time $1,5,10,20,30$, and 60 minutes using all the points within this range. The secondary rate of water absorption $\left(\mathrm{mm} / \mathrm{S}^{1 / 2}\right)$ is described as the slope of the line that is the best fit to the water absorption graph plotted against the square root of time $\left(S^{1 / 2}\right) 1,2,3,4,5,6$ and 7 days using all the points from $1 d$ to $7 d[16]$. 
Tab. 4 - water absorption of BFRC

\begin{tabular}{|l|l|l|l|l|l|}
\hline \multicolumn{2}{|c|}{ Observed time } & \multicolumn{4}{|c|}{ Water absorption $(\mathrm{mm})$} \\
\hline Time $(\mathrm{s})$ & $\sqrt{\text { time }}\left(s^{1 / 2}\right)$ & $0 \%$ Fiber & $0.3 \%$ Fiber & $0.6 \%$ Fiber & $0.9 \%$ Fiber \\
\hline 0 & 0 & 0.0000 & 0.0000 & 0.0000 & 0.0000 \\
\hline 60 & 8 & 0.3348 & 0.3348 & 0.5580 & 0.5580 \\
\hline 300 & 17 & 0.1860 & 0.5208 & 0.5580 & 0.5580 \\
\hline 600 & 24 & 0.1860 & 0.7068 & 0.7440 & 0.7440 \\
\hline 1200 & 35 & 0.3720 & 0.7068 & 0.9301 & 0.7440 \\
\hline 1800 & 42 & 0.3720 & 0.7068 & 0.9301 & 0.9301 \\
\hline 3600 & 60 & 0.5580 & 1.0788 & 1.3021 & 1.1161 \\
\hline 7200 & 85 & 0.5580 & 1.2649 & 1.4881 & 1.1161 \\
\hline 10800 & 104 & 0.7440 & 1.4509 & 1.6741 & 1.4881 \\
\hline 14400 & 120 & 0.9300 & 1.4509 & 1.8601 & 1.4881 \\
\hline 18000 & 134 & 1.1161 & 1.4509 & 1.8601 & 1.4881 \\
\hline 21600 & 147 & 1.3021 & 1.6369 & 2.0461 & 1.6741 \\
\hline 99420 & 315 & 1.4881 & 2.1949 & 2.7901 & 2.0461 \\
\hline 196620 & 443 & 1.6741 & 2.3801 & 2.9762 & 2.2321 \\
\hline 272220 & 522 & 1.6741 & 2.5670 & 2.9762 & 2.2321 \\
\hline 355020 & 596 & 1.4881 & 2.7530 & 3.1622 & 2.4181 \\
\hline 529980 & 728 & 1.6742 & 2.7530 & 3.3482 & 2.4181 \\
\hline 6223580 & 790 & 1.6742 & 2.7530 & 3.3482 & 2.6041 \\
\hline & & & & & \\
\hline
\end{tabular}

Tab. 5 - water absorption of PFRC

\begin{tabular}{|l|l|l|l|l|l|}
\hline \multicolumn{3}{|c|}{ Observed time } & \multicolumn{4}{c|}{ Water absorption I (mm) } \\
\hline Time $(\mathrm{s})$ & $\sqrt{\text { time }}\left(s^{1 / 2}\right)$ & $0 \%$ Fiber & $0.3 \%$ Fiber & $0.6 \%$ Fiber & $0.9 \%$ Fiber \\
\hline 0 & 0 & 0.0000 & 0.0000 & 0.0000 & 0.0000 \\
\hline 60 & 8 & 0.3348 & 0.5580 & 0.7440 & 0.1860 \\
\hline 300 & 17 & 0.1860 & 0.5580 & 0.7440 & 0.1860 \\
\hline 600 & 24 & 0.1860 & 0.7440 & 0.9301 & 0.5580 \\
\hline 1200 & 35 & 0.3720 & 0.7440 & 0.1161 & 0.5580 \\
\hline 1800 & 42 & 0.3720 & 0.7440 & 0.1161 & 0.7440 \\
\hline 3600 & 60 & 0.5580 & 0.9301 & 1.3021 & 0.9301 \\
\hline 7200 & 85 & 0.5580 & 1.4881 & 1.4881 & 0.9301 \\
\hline 10800 & 104 & 0.7440 & 1.4881 & 1.8601 & 0.9301 \\
\hline 14400 & 120 & 0.9300 & 1.4881 & 1.8601 & 0.1161 \\
\hline 18000 & 134 & 1.1161 & 1.4881 & 2.0461 & 0.1161 \\
\hline
\end{tabular}




\begin{tabular}{|l|l|l|l|l|l|}
\hline 21600 & 147 & 1.3021 & 1.6741 & 2.0461 & 1.3021 \\
\hline 99420 & 315 & 1.4881 & 2.7902 & 2.4181 & 1.6741 \\
\hline 196620 & 443 & 1.6741 & 2.7962 & 2.6041 & 1.6741 \\
\hline 272220 & 522 & 1.6741 & 2.7902 & 2.4181 & 1.6742 \\
\hline 355020 & 596 & 1.4881 & 2.9762 & 2.6041 & 1.6742 \\
\hline 529980 & 728 & 1.6742 & 2.9762 & 2.6041 & 1.6742 \\
\hline 623580 & 790 & 1.6742 & 3.1622 & 2.6041 & 1.8601 \\
\hline 717180 & 847 & 1.8601 & 3.1622 & 2.6041 & 1.8601 \\
\hline
\end{tabular}

Tab. 6 - water absorption of SFRC

\begin{tabular}{|l|l|l|l|l|l|}
\hline \multicolumn{3}{|c|}{ Observed time } & \multicolumn{4}{c|}{ Water absorption I $(\mathrm{mm})$} \\
\hline Time $(\mathrm{s})$ & $\sqrt{\text { time }}\left(s^{1 / 2}\right)$ & $0 \%$ Fiber & $0.3 \%$ Fiber & $0.6 \%$ Fiber & $0.9 \%$ Fiber \\
\hline 0 & 0 & 0.0000 & 0.0000 & 0.0000 & 0.0000 \\
\hline 60 & 8 & 0.3348 & 0.1860 & 0.3720 & 0.0000 \\
\hline 300 & 17 & 0.1860 & 0.3720 & 0.3720 & 0.0000 \\
\hline 600 & 24 & 0.1860 & 0.3720 & 0.3720 & 0.1860 \\
\hline 1200 & 35 & 0.3720 & 0.3720 & 0.5580 & 0.3720 \\
\hline 1800 & 42 & 0.3720 & 0.3720 & 0.5580 & 0.3720 \\
\hline 3600 & 60 & 0.5580 & 0.5580 & 0.5580 & 0.3720 \\
\hline 7200 & 85 & 0.5580 & 0.7440 & 0.5580 & 0.3720 \\
\hline 10800 & 104 & 0.7440 & 0.7440 & 0.5580 & 0.7440 \\
\hline 14400 & 120 & 0.9300 & 0.9301 & 0.5580 & 0.7440 \\
\hline 18000 & 134 & 1.1161 & 0.9301 & 0.7440 & 0.7440 \\
\hline 21600 & 147 & 1.3021 & 0.1161 & 0.7440 & 0.9301 \\
\hline 99420 & 315 & 1.4881 & 1.4881 & 0.7440 & 0.1161 \\
\hline 196620 & 443 & 1.6741 & 1.4881 & 0.9301 & 1.3021 \\
\hline 272220 & 522 & 1.6741 & 1.4881 & 0.9301 & 1.3021 \\
\hline 355020 & 596 & 1.4881 & 1.4881 & 0.9301 & 1.3021 \\
\hline 529980 & 728 & 1.6742 & 1.4881 & 1.3021 & 1.3021 \\
\hline 623580 & 790 & 1.6742 & 1.6742 & 1.3021 & 1.3021 \\
\hline 717180 & 847 & 1.8601 & 1.6742 & 1.3021 & 1.3021 \\
\hline
\end{tabular}

The concrete mixture absorption rates incorporated with different fibers at various intervals were proportional to the square root of time linearly at the initial stage. Among the fiber type, steel fiber is more resistant to capillary suction in various mixtures than basalt fiber. However, polypropylene for both mix ratios indicates the fastest absorption rate for the initial period. The basalt showed an accelerated degree of absorption for secondary absorption compared to steel fiber and control. 
As shown in Figure 3, the absorption rate of BFRC specimens is higher than non-fibrous samples. The inclusion of basalt fiber at $0.6 \%$ volume fraction shows the highest absorption at the initial and secondary stage of absorption with values $2 \mathrm{~mm}$ and $3.6 \mathrm{~mm}$, respectively. The absorption rate of specimens containing $0.9 \%$ basalt fiber was lower than the absorption of samples incorporated with $0.3 \%$ basalt fiber. The case is different in PFRC specimens, whereby specimen with $0.3 \%$ polypropylene fiber exhibits the highest absorption rate. The absorption rate decreases with an increase in polypropylene fiber, as shown in Figure 4. The steel fiber reinforced concrete revealed that the control sample has the highest absorption rate, and the specimen containing $0.9 \%$ steel fiber had the lowest absorption capacity, as depicted in Figure 5.

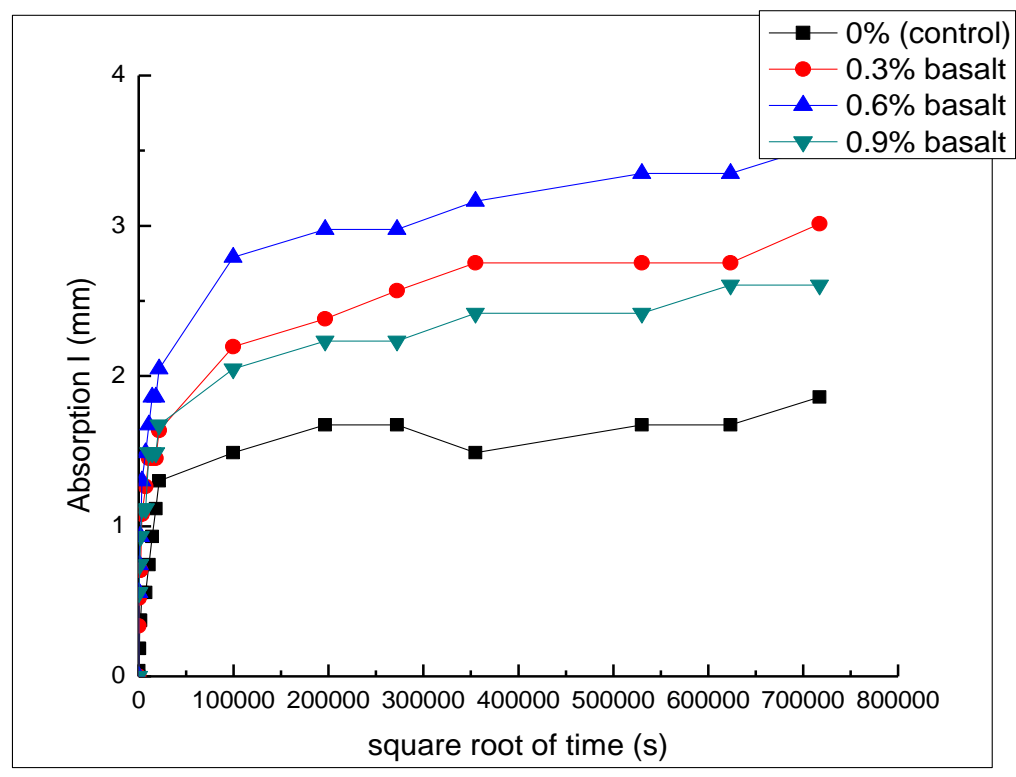

Fig. 3- Rate of absorption against the square root of time for BFRC

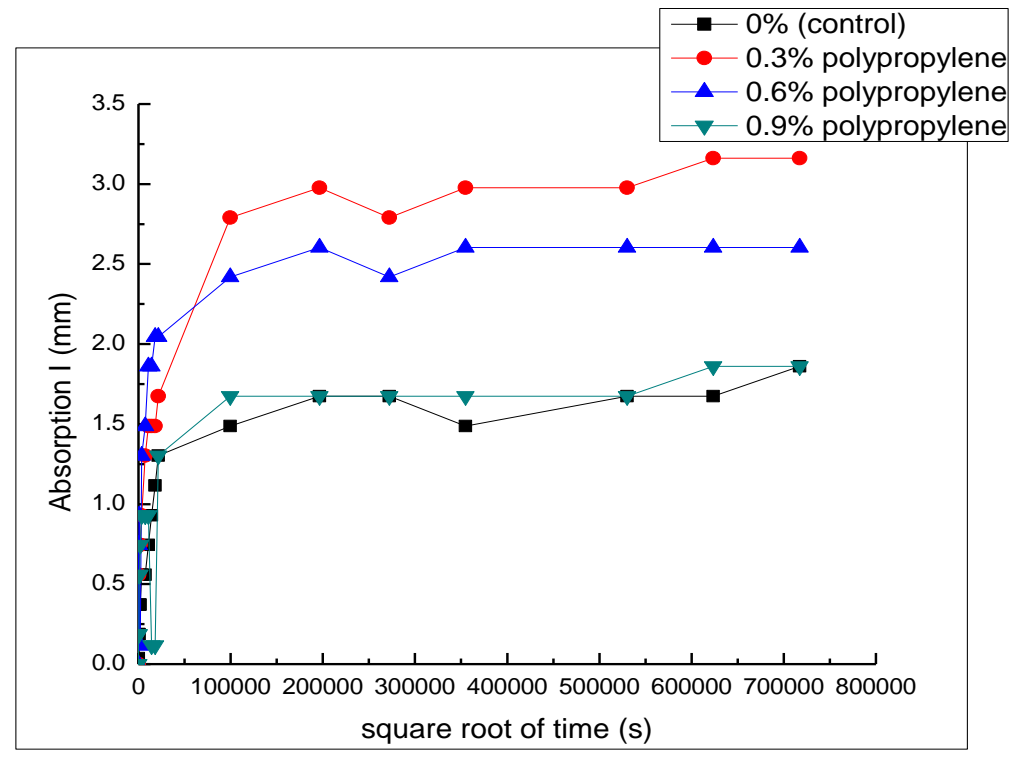

Fig. 4- Rate of absorption against the square root of time for PFRC 


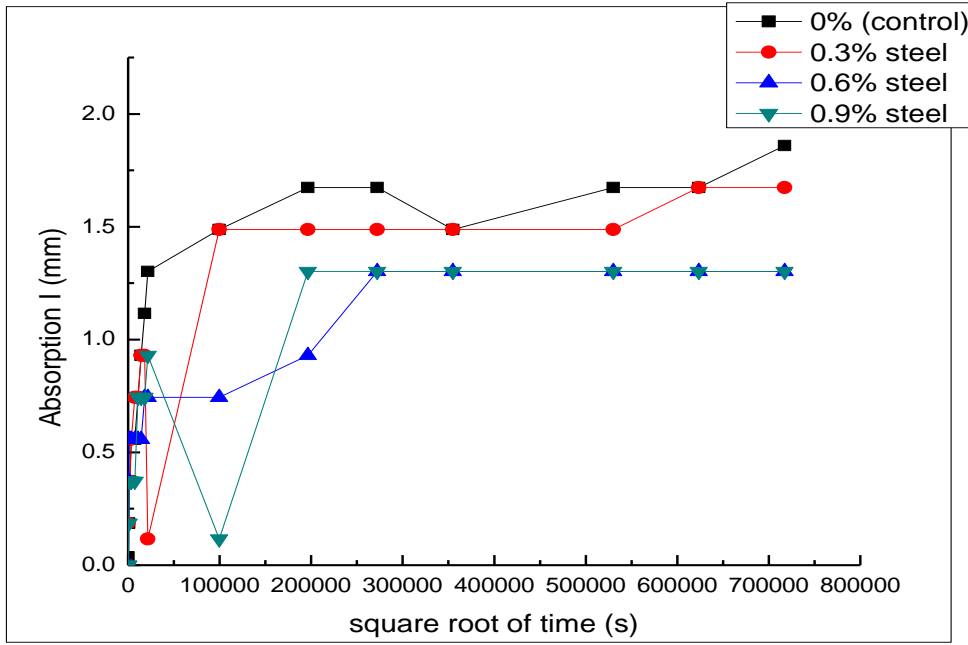

Fig. 5- Rate of absorption against the square root of time for SFRC

\section{Effect of Fibers on the rate of absorption at initial and final stages}

Figures 6 and 7 show the comparison of initial and secondary absorption for non-fibrous and fiber reinforced concrete. Generally, incorporating fibers into the concrete mixtures compared to the reference specimens leads to a significant decrease in water absorption rate regardless of the fiber type at an initial stage. It can be seen, at 0.3 and $0.6 \%$ of polypropylene fiber, the amount of water absorption remains the same and further reduce at $0.9 \%$ volume fraction. A nearly constant reduction of the absorption rate was revealed at the three different volume fractions of basalt fiber at an early absorption stage. However, in SFRC, the water absorption decreases with an increase in steel fiber. At the secondary stage, the absorption rate of plain, BFRC, PFRC, and SFRC specimens demonstrate similar behavior. However, the steel fiber reinforced concrete specimens revealed a significant decrease in the absorption rate at all levels of increment of steel fiber, presumably attributed to steel fiber's metallic nature.

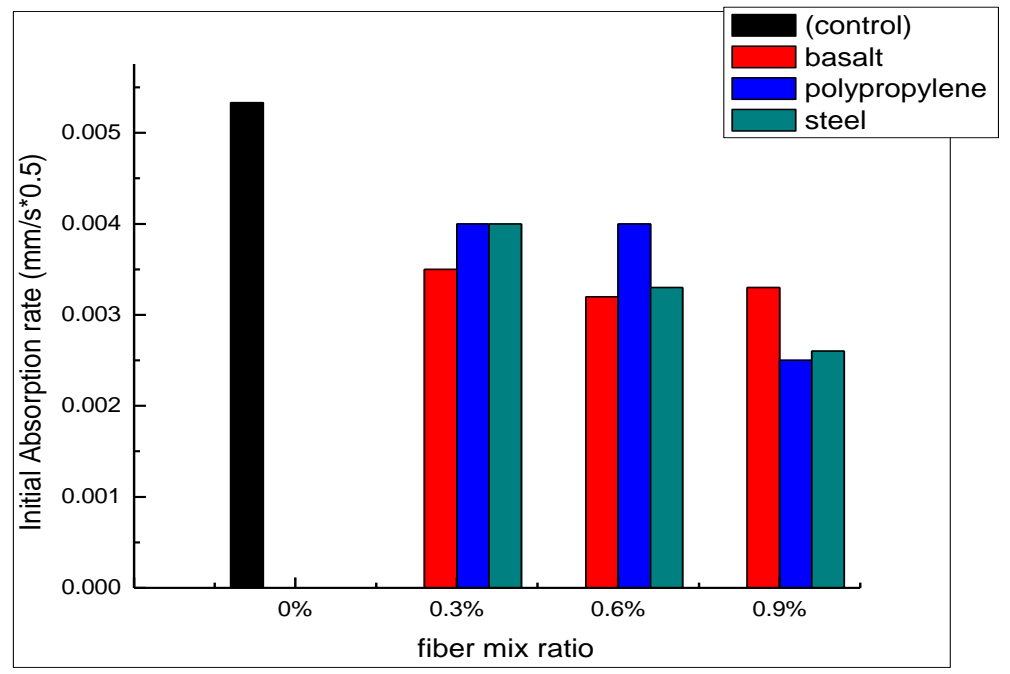

Fig. 6- Initial absorption vs. fiber mix ratio for Plain, BFRC, PFRC, and SFRC. 


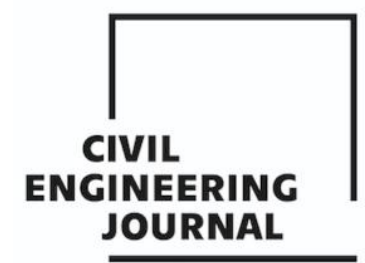

Article no. 31

THE CIVIL ENGINEERING JOURNAL 2-2021

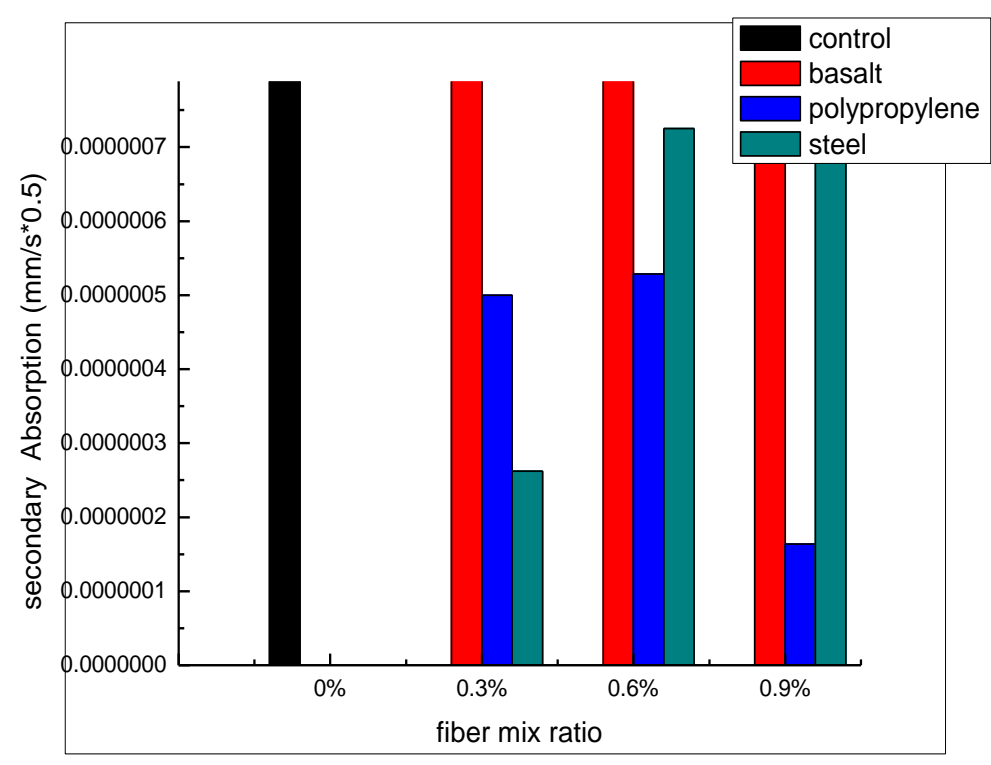

Fig. 7- Secondary absorption vs. fiber mix ratio for Plain, BFRC, PFRC, and SFRC

\section{CONCLUSION}

In this study, the effect of fiber volume fraction and fiber types was experimentally investigated to determine the water absorption rate in the concrete mixtures. The need to overcome the problem of degradation of concrete by the mass movement of water into concrete structures. The following conclusions can be drawn:

- The absorption rate for each type and each volume of fiber were linearly proportional to the square root of time.

- The addition of basalt, polypropylene, and steel fiber in different volume ratios showed a significant decrease in the initial absorption rate. However, basalt showed no notable change with secondary absorption, while steel and polypropylene showed little secondary absorption.

- Among the fiber reinforced concrete specimens, SFRC showed the highest resistance to the capillary action compare to reference samples, which might result from relatively stable bonding, which blocked water from traveling between fiber and hardened cement paste. However, BFRC and PRFC revealed a high absorption rate than SFRC because PRFC significantly accelerated water transport into concrete; this is presumably due to interfacial transition zone resulting from incorporating polypropylene fiber in the mixture, thin and long hydrophobic behavior.

\section{REFERENCES}

[1] M. Abdulhadi, A comparative Study of Basalt and Polypropylene Fibers Reinforced Concrete on Compressive and Tensile Behavior, Int. J. Eng. Trends Technol. 9 (2014) 295-300. https://doi.org/10.14445/22315381/ijett-v9p258.

[2] R. Punyamurthy, D. Sampathkumar, R.P.G. Ranganagowda, B. Bennehalli, C. V Srinivasa, Mechanical properties of abaca fiber reinforced polypropylene composites: Effect of chemical treatment by benzene diazonium chloride, J. King Saud Univ. - Eng. Sci. 29 (2017) 289-294. https://doi.org/https://doi.org/10.1016/j.jksues.2015.10.004.

[3] A.N.S. Al-Qadi, S.M. Al-Zaidyeen, Effect of fiber content and specimen shape on the residual strength of polypropylene fiber self-compacting concrete exposed to elevated temperatures, J. King Saud Univ. - Eng. Sci. 26 (2014) 33-39. https://doi.org/https://doi.org/10.1016/j.jksues.2012.12.002. 


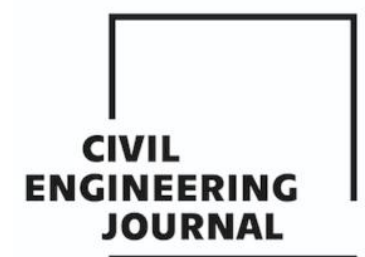

Article no. 31

THE CIVIL ENGINEERING JOURNAL 2-2021

[4] M.I. Khan, Y.M. Abbas, G. Fares, Review of high and ultrahigh performance cementitious composites incorporating various combinations of fibers and ultrafine, J. King Saud Univ. - Eng. Sci. 29 (2017) 339-347. https://doi.org/https://doi.org/10.1016/j.jksues.2017.03.006.

[5] H. Prayuda, F. Monika, M. Dwi Cahyati, F. Saleh, Self Fiber Compacting Concrete (SFCC) Properties Incorporated With Silica Fume and Fiber, Stavební Obz. - Civ. Eng. J. 29 (2020) 52-60. https://doi.org/10.14311/cej.2020.01.0005.

[6] M. Abdulhadi, M.S. Labbo, Comparative Study on the Effect of Sodium Chloride NaCl Solution as Curing Medium of Basalt, Polypropylene and Steel Fiber Reinforced Concrete on Compressive Strength, 6 (2016) 4750-4756. https://doi.org/10.4010/2016.1180.

[7] M. İpek, Examination of the Usability of Basalt Aggregate in Sifcon, Stavební Obz. - Civ. Eng. J. 27 (2018) 500-512. https://doi.org/10.14311/cej.2018.04.0040.

[8] Y. Zhang, Study on Anti-Cracking Performance Evaluation Method of Steel Fiber Reinforced Ceramsite Concrete (Sfrcc) Based on Partly-Restrained Shrinkage Ring, Stavební Obz. - Civ. Eng. J. 26 (2017) 394-403. https://doi.org/10.14311/cej.2017.04.0033.

[9] B. Bhushan Jindal, P. Jangra, A. Garg, 2020. Effects of ultrafine slag as mineral admixture on the compressive strength, water absorption, and permeability of rice husk ash-based geopolymer concrete, Mater. Today Proc. vol. 32 871-877. doi.org/10.1016/j.matpr.2020.04.219.

[10] J. a. Kropp, Performance criteria for concrete durability, n RILEM Report 12., London: E\&FN Spon., 1995.

[11] B.B. Sabir, S. Wild, M. O'Farrell, A water sorptivity test for mortar and concrete, Mater. Struct. 31 (1998) 568. https://doi.org/10.1007/BF02481540.

[12] J. Castro, D. Bentz, J. Weiss, Effect of sample conditioning on the water absorption of concrete, Cem. Concr. Compos. 33 (2011) 805-813. https://doi.org/https://doi.org/10.1016/j.cemconcomp.2011.05.007.

[13] R.J. Gummerson, C. Hall, W.D. Hoff, Water movement in porous building materials-II. Hydraulic suction and sorptivity of brick and other masonry materials, Build. Environ. 15 (1980) 101-108. https://doi.org/https://doi.org/10.1016/0360-1323(80)90015-3.

[14] JGJ52-2006, Chinese National Standards, for technical requirements and test method of sand and crushed stone for ordinary concrete, n.d.

[15] 2011. JGJ55, Chinese National Standards. Specification for mix proportion design of Ordinary concrete, n.d.

[16] A. C1585-04, Standard Test Method for Measurement of Rate of Absorption of Water by HydraulicCement Concretes, ASTM Int. (2004).

[17] Niveditha, M. and Srikanth, K. Effect of Durability properties on Geopolymer concrete - A Review E3S Web of Conference 184, 01092 (2020), ICMED 2020. https://doi.org/10.1051.e3sconf/202018401092 